\title{
Lung Lesion Segmentation Using Gaussian Filter and Discrete Wavelet Transform
}

\author{
Kamil Dimililer ${ }^{1}$, Ali Hesri ${ }^{1}$ and Yoney Kirsal Ever ${ }^{2}$ \\ ${ }^{1}$ Electric and Electronic Engineering Department, Near East University, North Cyprus, Mersin 10 Turkey \\ ${ }^{2}$ Software Engineering Department, Near East University, North Cyprus, Mersin 10 Turkey
}

\begin{abstract}
Lung cancer is the growth of a tumour, referred to as a nodule that arises from cells covering the airways of the respiratory arrangement. Effective detection of lung cancer at premature stages enables any cure options, and reduce risk of insidious surgery and increased continued existence rate. Recently, image processing techniques are extensively used in different medical areas for lung tumour image improvement in early detection and cure stages. This is due to the importance of the time factor of discovering the abnormality issues in target images. The developed system is mainly an algorithm combining different image processing techniques such as filtering, erosion, discrete wavelets transform, and thresholding. However, the main aim of this work is to investigate the effectiveness of different filters along with different types of discrete wavelets toward an accurate segmentation of a lung tumour in a CT image. The experimental results of the developed system show that the use of Gaussian filter with the Haar wavelets is the best for such segmentation task.
\end{abstract}

\section{Introduction}

Lung cancer is thought to be the fundamental driver of cancer death around the world, and in its initial stages it is hard to identify considering the fact, that lone in the propelled organize side effects show up bringing about the death rate to be the most astounding among every single other sort of cancer [1]. In the event of lung knobs can be distinguished precisely at an early stage, the patient's survival rate can be expanded by a noteworthy rate. The rank request of cancers for both guys and females among Jordanians in 2008 demonstrated that there were 356 instances of lung cancer representing $(7.7 \%)$ of all recently analysed cancer cases in 2008 [14]. Lung cancer influenced 297 (13.1\%) guys and 59 $(2.5 \%)$ females with a male to female proportion of 5:1 where lung cancer positioned second among males and tenth among females [20], [23].

The humankind pace of lung cancer is the most extreme among every single other kind of cancer. Lung cancer is one of the grimmest cancers on the planet, with the littlest proceeded with presence rate after the judgement, with a moderate yet beyond any doubt increment in the quantity of passing consistently. Writing has an extensive variety of segmentation strategies utilized as a part of lung cancer conclusion. Picture processing has wide extension in medicinal picture processing for diagnosing the lung cancer [1], [23]. The reason for this paper is to audit related work on programmed conclusion of lung cancer and run-down different segmentation and characterization methods for discovery of lung nodules. The detection of lung cancer should be possible in various routes, for 
example, Computed Tomography (CT), Magnetic Resonance Imaging (MRI), X-rays and sputum cytology [21], [22].

Utilizing image processing methods like pre-processing and highlight extraction, area of interest is isolated. Building up the algorithm, features like area, limit, intensity and entropy are computed from every one of the images. Tumours are characterized into two sorts. Benign tumour: Benign tumours are non-cancerous. They have a propensity to grow slowly and stay in one place, not spreading into other parts of the body. Benign tumours usually stay non-cancerous, except in very rare cases. Malignant tumour: Malignant tumours are cancerous. Cancer can commence in any one of the trillions of cells in our body. Frequently in our body new cells are generated and old cells or damaged cell will die.

\section{Methodology}

The developed system is to segment the lung tumour in CT images. Different image processing techniques are used to reach that goal. The images first were filtered to reduce the noise found in them and to increase their intensity pixels. In later stages, the enhanced images undergo wavelets transform techniques to extract 4 different output images that represent the horizontal, vertical, approximation, and the diagonal images. These 4 images are then summed to the reconstructed image which is the image inverse wavelet image.

The last stage is when the summed image is eroded, thresholded and then the subtraction operation takes place so that the tumour is segmented. As can be seen in figure 1 the developed segmentation system consists of different techniques that eventually lead to the lung tumour segmentation. For this purpose, two types of filters are used in addition to many types of wavelets transform as well. The results of each version of the system are different and they will be discussed in next chapters.

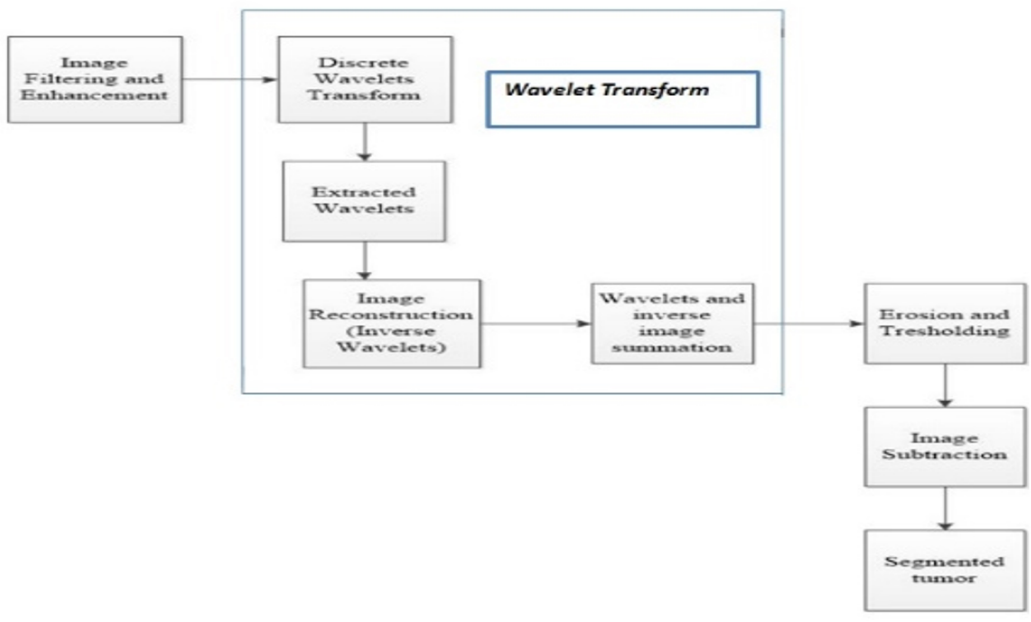

Figure 1. Proposed system flowchart.

\subsection{Stage 1: Filtering of images and results}

Median Filter: Median filter is utilized to lessen in-discreet commotion or the salt-and pepper noise in an image with keeping the helpful component and the edges of the image [1]. 

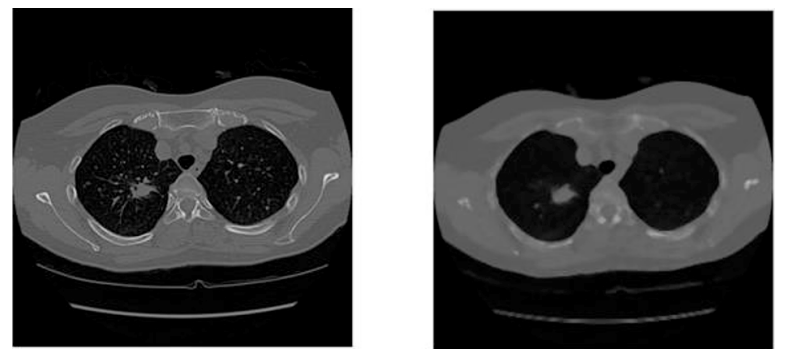

Figure 2. Median filtering.

Gaussian filter: The Gaussian filter is good when standard deviation is high since it blurring all parts which allows to the removal of the unwanted. However, applying high standard deviation is not always good for this segmentation task because the high blurring effect may also blur and the remove the tumour which is the region of interest which will lead to a low accuracy system. Therefore, the

standard was selected to be 0.8 which showed good results.
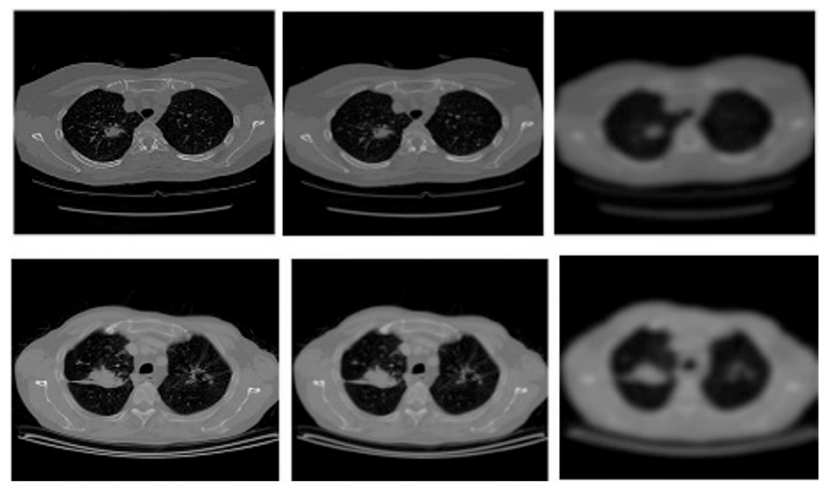

Figure 3. Gaussian filtering.

\subsection{Stage 2: Transformation Wavelet transform}

The wavelet transform is like the Fourier transform (or considerably more to the windowed Fourier transform) with a totally unique legitimacy function. The wavelet transformation of the image is shown below:

$$
F(a, b)=\int_{-\infty}^{\infty} f(x) \psi_{(a, b)}^{*}(x) \mathrm{d} x
$$

Discrete wavelet transform: The discrete wavelet transform (DWT) is a utilization of the wavelet transform using a discrete course of action of the wavelet scales and interpretations agreeing to some described guidelines. All things considered, this transform separates the banner into generally orthogonal course of action of wavelet, which is the essential difference from the consistent wavelet transform (CWT), or its execution for the discrete time game plan now and again called discrete-time constant wavelet transform (DT-CWT) [4]. 


$$
\phi(x)=\sum_{k=-\infty}^{\infty} a_{k} \phi(S x-k)
$$

where $\mathrm{S}$ is a scaling factor (which is usually selected to be 2).

$$
\int_{-\infty}^{\infty} \varnothing(x) \varnothing(x+l) \mathrm{d} x=\delta_{0, l}
$$

Haar Wavelet: The Haar wavelet is likewise the easiest conceivable wavelet. The specialized drawback of the Haar wavelet is that it is not continuous, and subsequently not differentiable.

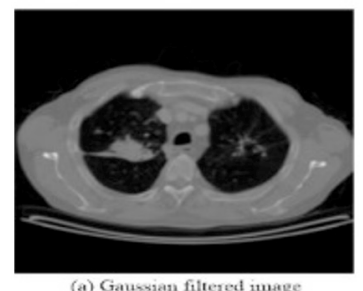

(a) Gaussian filtered image

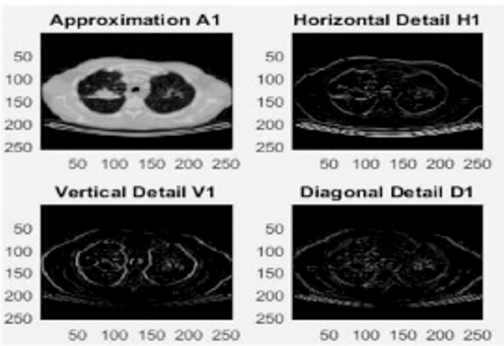

(b) Extracted wavelets

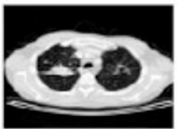

(c) Inverse discrete wavelet tranform

Figure 4. Haar wavelet transform with Gaussian filter.

The Haar wavelet's wavelet function $\psi(t)$ can be depicted as:

$$
\psi(t)= \begin{cases}1 & 0 \leq t<\frac{1}{2} \\ -1 & \frac{1}{2} \leq t<1 \\ 0 & \text { otherwise }\end{cases}
$$

Bi-orthogonal discrete wavelet: Bi-orthogonal wavelets highlight a couple of scaling functions and related scaling channels one for examination and one for union.

It can be utilized the wavelet with the more noteworthy number of vanishing minutes for examination bringing about a meagre representation, while the smoother wavelet for recreation is utilized.

Inverse discrete wavelet transform: The Haar transform $y n$ of an n-input function $x n$ is

$$
\mathrm{y}_{n}=H_{n} x_{n}
$$

The Haar transform matrix is real and orthogonal. Thus, the inverse Haar transform can be derived [19].

\subsection{Stage 3: Summation of enhanced images}


After getting the 4 different wavelets from the image, the image is reconstructed using the inverse discrete wavelets transform. Then, these images are summed together to obtain a clearer and enhanced image where the tumour is well defined and separated from the other parts of the image. This addition operation helps to segment the tumour in later [12].

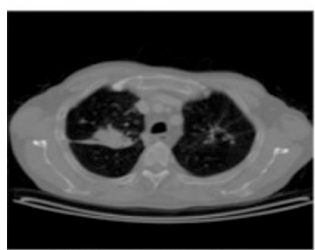

(a) Gaussian filtered mage

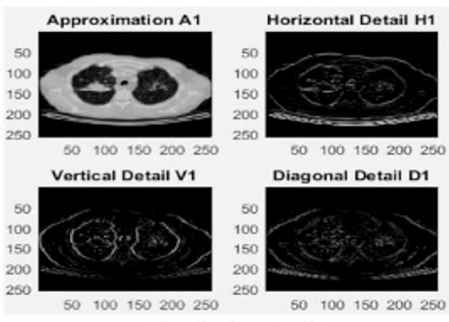

(b) Extracted wavelets

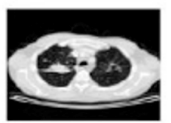

(c) Inverse discrete wavelet tranform

Figure 5. Biorthogonal discrete wavelet transform with Gaussian filter.

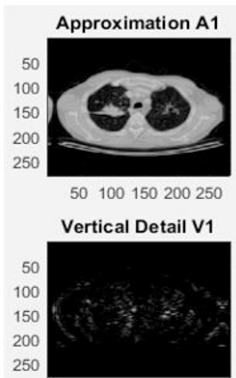

50100150200250

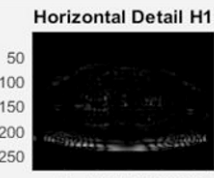

50100150200250

Diagonal Detail D1

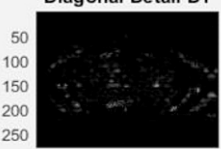

50100150200250

$+$

Inverse wavelet image

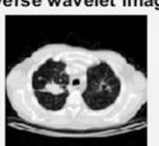

Figure 6. Summation of Haar wavelet and reconstructed image.

The filter used here is the Gaussian filter. 


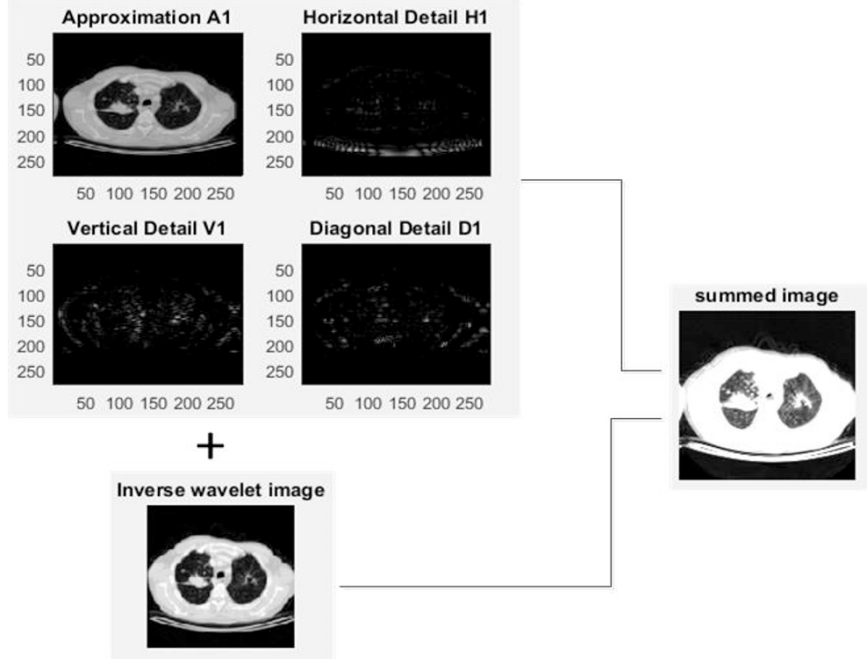

Figure 7. Summation of "Bior 3.7" wavelets and reconstructed image.

The filter used here is the median filter.

\subsection{Stage 4: Erosion}

Morphology technique can be de-fined as a group of image processing operations that process images based on shapes. These morphological operations depend on applying an organizing component to an input image with a specific end goal to make a yield image of a similar size [15].

\subsection{Stage 5: Thresholding}

Thresholding is the detachment of district of images into two areas. One district compares to the frontal area locale, in which it contains the articles that we are keen on. The other area is the foundation, compares to the un-needed items [14].

Amid thresholding, every pixel is contrasted with that edge value. On the off chance that the pixel value is more prominent than that edge, then this pixel is considered as frontal area pixel (white). In the event, that the pixel value is lower than that limit value, then the pixel is considered as foundation pixel (black) [1].

\subsection{Stage 6: Image subtraction}

Image subtraction is a basic tool for the analysis, processing, and interpreting of medical images.

\section{Results and discussions}

The developed system was tested on 70 images. Among them, 50 are lung images with tumour, and 20 are non-tumour images. The same images were used for testing the different versions of the developed system to investigate the effectiveness of each. For each version of the developed system the accuracy of the tumour and non-tumour lungs were calculated. Then the total accuracy was calculated.

The accuracy was defined as the number of the correctly segmented tumours divided by the total number of images. 


$$
A C C=P / N
$$

where $P$ is the number correctly segmented images, and $N$ is the total number of images. The tables below show the accuracies of the system developed.

- Table 1 shows the accuracy of the system when the Gaussian filters and Haar wavelet type used

- Table 2 shows the accuracy of the system when the Median filter and Haar wavelet type is used.

- The table 3 shows the Bi-orthogonal 3.7 wavelets along with the median filter.

- Table 4 shows the same wavelets type but within the Gaussian filter.

- The table 5 and 6 show the median filter and Gaussian filter with the Bi-orthogonal 3.5 wavelets

- $\quad$ The table 7 shows the use of median filter together with the Db7 wavelets.

Table 1. Gaussian filter and Haar wavelet.

\begin{tabular}{|c|c|c|c|c|}
\hline Dataset & Filter type & $\begin{array}{c}\text { Discrete } \\
\text { Wavelet } \\
\text { transform } \\
\text { type }\end{array}$ & $\begin{array}{c}\text { Correctly } \\
\text { segmented } \\
\text { images }\end{array}$ & $\begin{array}{c}\text { Total } \\
\text { Recognition }\end{array}$ \\
\hline $\begin{array}{c}\text { Abnormal images } \\
(50)\end{array}$ & Gaussian filter & Haar wavelet & $46 / 50$ & $96 \%$ \\
\hline $\begin{array}{c}\text { Normal images } \\
(20)\end{array}$ & Gaussian filter & Haar wavelet & $20 / 20$ & $100 \%$ \\
\hline $\begin{array}{c}\text { System } \\
\text { Performance }\end{array}$ & \multicolumn{3}{|c|}{$96 \%$} \\
\hline
\end{tabular}

Table 2. Median filter and Haar wavelet.

\begin{tabular}{|c|c|c|c|c|}
\hline Dataset & Filter type & $\begin{array}{c}\text { Discrete } \\
\text { Wavelet } \\
\text { transform } \\
\text { type }\end{array}$ & $\begin{array}{c}\text { Correctly } \\
\text { segmented } \\
\text { images }\end{array}$ & $\begin{array}{c}\text { Total } \\
\text { Recognition }\end{array}$ \\
\hline $\begin{array}{c}\text { Abnormal } \\
\text { images (50) }\end{array}$ & Median filter & Haar wavelet & $39 / 50$ & $78 \%$ \\
\hline $\begin{array}{c}\text { Normal images } \\
(20)\end{array}$ & Median filter & Haar wavelet & $20 / 20$ & $100 \%$ \\
\hline $\begin{array}{c}\text { System } \\
\text { Performance }\end{array}$ & \multicolumn{3}{|c|}{$89 \%$} \\
\hline
\end{tabular}

Table 3. Gaussian filter and Bi-orthogonal 3.7 wavelet.

\begin{tabular}{|c|c|c|c|c|}
\hline Dataset & Filter type & $\begin{array}{c}\text { Discrete } \\
\text { Wavelet } \\
\text { transform } \\
\text { type }\end{array}$ & $\begin{array}{c}\text { Correctly } \\
\text { segmented } \\
\text { images }\end{array}$ & $\begin{array}{c}\text { Total } \\
\text { Recognition }\end{array}$ \\
\hline $\begin{array}{c}\text { Abnormal } \\
\text { images (50) }\end{array}$ & Gaussian filter & $\begin{array}{c}\text { Bi-orthogonal } \\
3.7\end{array}$ & $43 / 50$ & $86 \%$ \\
\hline $\begin{array}{c}\text { Normal images } \\
(20)\end{array}$ & Gaussian filter & $\begin{array}{c}\text { Bi-orthogonal } \\
3.7\end{array}$ & $20 / 20$ & $100 \%$ \\
\hline $\begin{array}{c}\text { System } \\
\text { Performance }\end{array}$ & \multicolumn{3}{|c|}{$93 \%$} \\
\hline
\end{tabular}


Table 4. Median filter and Bi-orthogonal 3.7 wavelet.

\begin{tabular}{|c|c|c|c|c|}
\hline Dataset & Filter type & $\begin{array}{c}\text { Discrete } \\
\text { Wavelet } \\
\text { transform } \\
\text { type }\end{array}$ & $\begin{array}{c}\text { Correctly } \\
\text { segmented } \\
\text { images }\end{array}$ & $\begin{array}{c}\text { Total } \\
\text { Recognition }\end{array}$ \\
\hline $\begin{array}{c}\text { Abnormal } \\
\text { images (50) }\end{array}$ & Median filter & $\begin{array}{c}\text { Bi-orthogonal } \\
3.7\end{array}$ & $44 / 50$ & $88 \%$ \\
\hline $\begin{array}{c}\text { Normal images } \\
(20)\end{array}$ & Median filter & $\begin{array}{c}\text { Bi-orthogonal } \\
3.7\end{array}$ & $20 / 20$ & $100 \%$ \\
\hline $\begin{array}{c}\text { System } \\
\text { Performance }\end{array}$ & \multicolumn{4}{|c|}{$94 \%$} \\
\hline
\end{tabular}

Table 5. Median filter and Bi-orthogonal 3.5 wavelet.

\begin{tabular}{|c|c|c|c|c|}
\hline Dataset & Filter type & $\begin{array}{c}\text { Discrete } \\
\text { Wavelet } \\
\text { transform } \\
\text { type }\end{array}$ & $\begin{array}{c}\text { Correctly } \\
\text { segmented } \\
\text { images }\end{array}$ & $\begin{array}{c}\text { Total } \\
\text { Recognition }\end{array}$ \\
\hline $\begin{array}{c}\text { Abnormal } \\
\text { images (50) }\end{array}$ & Median filter & $\begin{array}{c}\text { Bi-orthogonal } \\
3.5\end{array}$ & $42 / 50$ & $84 \%$ \\
\hline $\begin{array}{c}\text { Normal images } \\
(20)\end{array}$ & Median filter & $\begin{array}{c}\text { Bi-orthogonal } \\
3.5\end{array}$ & $20 / 20$ & $100 \%$ \\
\hline $\begin{array}{c}\text { System } \\
\text { Performance }\end{array}$ & \multicolumn{3}{|c|}{$92 \%$} \\
\hline
\end{tabular}

Table 6. Median filter and Db7 wavelet.

\begin{tabular}{|c|l|c|c|c|}
\hline Dataset & Filter type & $\begin{array}{c}\text { Discrete } \\
\text { Wavelet } \\
\text { transform } \\
\text { type }\end{array}$ & $\begin{array}{c}\text { Correctly } \\
\text { segmented } \\
\text { images }\end{array}$ & $\begin{array}{c}\text { Total } \\
\text { Recognition }\end{array}$ \\
\hline $\begin{array}{c}\text { Abnormal } \\
\text { images (50) }\end{array}$ & Median filter & Db7 wavelet. & $38 / 50$ & $76 \%$ \\
\hline $\begin{array}{c}\text { Normal images } \\
(20)\end{array}$ & Median filter & Db7 wavelet. & $17 / 20$ & $85 \%$ \\
\hline $\begin{array}{c}\text { System } \\
\text { Performance }\end{array}$ & \multicolumn{3}{|c|}{$80.5 \%$} \\
\hline
\end{tabular}

Table 7. Median filter and Db4 wavelet.

\begin{tabular}{|c|c|c|c|c|}
\hline Dataset & Filter type & $\begin{array}{c}\text { Discrete } \\
\text { Wavelet } \\
\text { transform } \\
\text { type }\end{array}$ & $\begin{array}{c}\text { Correctly } \\
\text { segmented } \\
\text { images }\end{array}$ & $\begin{array}{c}\text { Total } \\
\text { Recognition }\end{array}$ \\
\hline $\begin{array}{c}\text { Abnormal } \\
\text { images (50) }\end{array}$ & Median filter & Db4 wavelet & $41 / 50$ & $82 \%$ \\
\hline $\begin{array}{c}\text { Normal images } \\
(20)\end{array}$ & Median filter & Db4 wavelet & $18 / 20$ & $90 \%$ \\
\hline $\begin{array}{c}\text { System } \\
\text { Performance }\end{array}$ & \multicolumn{4}{|c|}{$91 \%$} \\
\hline
\end{tabular}

The experimental results of the developed system show that the use of Gaussian filter with the Haar wavelet is the best for such segmentation task. This is shows in table 1 where the accuracy is the highest $96 \%$. It can be seen that, the use of median filter with Haar wavelet lead to less effectiveness in segmenting the tumour where the accuracy is $89 \%$ shown in table 2 . The table 3 shows the use of Gaussian filter along with the Bi-orthogonal wavelet (Bior 3.7). this table shows an 93\% accuracy which is good but still less than the results shows in table 1 where Haar wavelet and Gaussian filter 
are used. The median filter was then used with the Bi-orthogonal wavelets (Bior 3.7), but the results were different here. The accuracy was $94 \%$ which is higher than the previous one where the Gaussian filter is used. This shows that Gaussian is not always good for getting higher accuracy. It depends on the type of wavelets transform used also. A different type of Bi-orthogonal wavelet was used (Bior 3.5) in table 5 with the median filter and the accuracy was $92 \%$ which is less than the Bior 3.7 accuracy although the same filter was used. In contrast, the median filter was also used with the Db4 wavelet transform in table 7 and it showed good segmentation results of $91 \%$ which is better than the results of table 6 where the $\mathrm{Db} 7$ is used. Thus, the results were always better when Haar wavelet type was used.

\section{Conclusions and future work}

This paper proposed method de-scribes a method for the segmentation lung tumour in CT scan images Thus it can be concluded that the proposed system performs fine and is robust against anatomical variations of the lungs. During the experiment, different discrete wavelet transforms were used with two types of filtering. After which, the Haar and Gaussian filtering with $96 \%$ accuracy was found to be the best. Thus, this algorithm showed an efficient and accurate result for segmenting the lung tumour in $\mathrm{CT}$ medical images and it will help radio-gist as second opinion for the better diagnosis of lung cancer.

\section{References}

1. Eng, H. L., and Ma, K. K. (2001).Noise adaptive soft-switching median filter, IEEE Transactions on Image Processing, 10(2), 242251.

2. Yujin, Z., (2006). Image Engineering (I): Image Processing. Second Edition. Japan: Tsinghua University Press.

3. Calderbank A. R., Daubechies I., Sweldens W., Yeo B. L.: Wavelet transforms that map integers to integers. Applied and Computational Harmonics Analysis, 5(3), 332369.

4. Daubechies, I. Recent results in wavelet applications. Journal of Electronic Imaging 7.4 (1998): 719-724.

5. Daubechies, I., \& Sweldens, W. (1998). Factoring wavelet transforms into lifting steps. Journal of Fourier analysis and applications, 4(3), 247-269.

6. Davis, G. M., \& Nosratinia, A. (1999). Wavelet-based image coding: an overview. In Applied and computational control, signals, and circuits (pp. 369-434). Birkhuser Boston.

7. Sonka M., Hlavac V., Boyle R.: Image processing, Analysis and Machine Vision. Brooks/Cole Publishing Comp.1999.

8. Haar, A. "Zur Theorie der orthogonalen Funktionen systeme", Math. Ann. 69, 331- 371, 1910.

9. Strang, G. "Wavelet Transforms Ver-sus Fourier Transforms", Bull. Amer. Math. Soc. 28, 288305, 1993.

10. Davis G., Strela V., Turcajova R.; Multi wavelet Construction via the Lifting Scheme. Wavelet Analysis and Multi resolution Methods, T. X. He (editor), Lecture Notes in Pure and Applied Mathematics, Marcel Dekker.

11. Kim, Y. T. (1997). Contrast enhancement using brightness preserving bi-histogram equalization. IEEE transactions on Consumer Electronics, 43(1), 1-8.

12. Wang, Y., Chen, Q., \& Zhang, B. (1999). Image enhancement based on equal area dualistic subimage histogram equalization method. IEEE Transactions on Consumer Electronics, 45(1), 68-75.

13. Seil, M., Obuz, F., Altay, C., Gencel, Igci, E., Sagol, ., \& Dicle, O. (2008). The role of dynamic subtraction MRI in detection of hypocellular carcinoma. Diagnostic and Interventional Radiology, 14(4), 2004.

14. Sezgin, M. (2004). Survey over image thresholding techniques and quantitative performance evaluation. Journal of Electronic imaging, 13(1), 146-168. 
15. Lim, Y. W., \& Lee, S. U. (1990). On the colour image segmentation algorithm based on the thresholding and the fuzzy c-means techniques. Pattern recognition, 23(9), 935-952.

16. Dimililer, K. (2013). Back propagation Neural Network Implementation for Medical Image Compression. Journal of Applied Mathematics.

17. Dimililer K (2012) "Neural network implementation for image compression of X- rays", Electronic World 118 (1911):26-29.

18. Khashman A., Dimililer K (2005) "Compression criteria for optimum Image compression", The International Conference on Computer as a Tool, 2005, dx.doi.rog/10.1109/EURCON. 2005.1630100.

19. Sonka M., Hlavac V., Boyle R.: Image processing, Analysis and Ma-chine Vision. Brooks/Cole Publishing Comp.1999.

20. Adnan Khashman, Boran Sekeroglu, Kamil Dimililer, "Intelligent Coin Identification System", Proceedings of the 2006 IEEE International Symposium on Intelligent Control Munich, Germany, (2006).

21. Dimililer, K., \& Ilhan A., Effect of image enhancement on mri brain images with neural networks, Proc Comp Sci, 102, 39-44 (2016)

22. Dimililer, K., Kirsal Ever, Y., \& Ratemi H., Intelligent eye tumour detection system, Proc Comp Sci, 102, 325-332 (2016)

23. Dimililer, K., Kirsal Ever, Y., \& Ugur B., ILTDS: Intelligent lung tumor detection system on ct images. Int J Intell Syst, 530, 225-235 (2016) 